\title{
PENGARUH KARAKTERISTIK ENGINE DALAM PENGGUNAAN BAHAN BAKAR BIODIESEL B-20 TERHADAP NILAI PERFORMANSI
}

\author{
(1)Puji Saksono, (2)Marsius Ferdnian \\ 1,2 Program Studi Teknik Mesin Fakultas Teknologi Industri Universitas Balikpapan \\ Jl. Pupuk Raya Balikpapan. Telp./Fax. 0542-764205 \\ Email:saksono_puji@yahoo.co.id,marsius.f.st@gmail.com
}

\begin{abstract}
Abstrak
Indonesia memiliki potensi yang besar untuk memproduksi bahan bakar alternatif sebagai pengganti bahan bakar minyak (BBM). Biodiesel merupakan salah satu bahan bakar alternatif yang dapat digunakan sebagai bahan bakar engine diesel. Tujuan penelitian adalah menganalisa pengaruh karakteristik engine dalam penggunaan bahan bakar biodiesel B-20 terhadap nilai performansi. Penelitian dilakukan melalui beberapa tahapan yaitu mulai dari pengumpulan data, proses overhoul engine, hingga ke proses pengujian performansi dengan dynamometer (dynotest). Peneliti melakukan pengujian dari beberapa jenis engine diesel pada unit alat berat yang digunakan pada perusahaan pertambangan dan marine. Pengujian dari beberapa unit engine yang diuji akan didapatkan bahwa untuk mencapai performansi tertinggi baik torsi dan daya tiap engine akan berbeda nilai putaran engine-nya. Hal ini dikarenakan sistem, teknologi, konstruksi dan tingkat kesempurnaan pembakaran di ruang bakar yang berbeda. Terjadi penurunan nilai performansi untuk semua engine dan jenis injection pump apapun yang digunakan pada saat menggunakan bahan bakar biodiesel B-20 dibandingkan dengan solar. Penurunan nilai performansi engine sangat berhubungan dengan karakteristik engine untuk dapat mengadaptasi perubahan typical characteristic dari bahan bakar biodiesel B20 yamg tentunya tidak sama seperti solar atau bahan bakar yang digunakan sebelumnya.
\end{abstract}

Kata kunci : Biodiesel B-20, dynotest engine, performansi

\begin{abstract}
Indonesia has great potential to produce alternative fuels as a substitute for fuel oil (BBM). Biodiesel is an alternative fuel that can be used as fuel for diesel engines. The research objective was to analyze the effect of engine characteristics in the use of biodiesel fuel B-20 on performance values. The research was carried out in several stages, starting from data collection, the engine overhoul process, to the performance testing process with a dynamometer (dynotest). Researchers conducted tests of several types of diesel engines in heavy equipment units used in mining and marine companies. Tests of several tested engine units will find that to achieve the highest performance both the torque and power of each engine will have different engine speed values. This is due to the different systems, technology, construction and level of combustion perfection in the combustion chamber. There is a decrease in the performance value for all engines and any type of injection pump used when using B-20 biodiesel as compared to diesel fuel. The decrease in the value of engine performance is closely related to the characteristics of the engine to be able to adapt to the typical characteristic changes of the B-20 biodiesel fuel which is certainly not the same as diesel or the fuel used previously.
\end{abstract}

Keywords: Biodiesel B-20, dynotest engine, performance 
p-ISSN 2502-4922,e-ISSN 2615-0867

\section{PENDAHULUAN}

Biodiesel merupakan jenis bahan bakar alternatif yang dapat diperbaharui dan ramah lingkungan. Bahan bakar ini terbuat dari minyak nabati yang kemudian diubah menjadi campuran bahan bakar pada minyak solar.

Tingkat aktifitas kegiatan di sektor pertambangan dan marine yang semakin tinggi dan jumlah unit alat berat yang semakin banyak, tentu saja penggunaan bahan bakar fosil jenis solar ini sangatlah dibatasi. Dengan adanya program pemerintah akan penghematan terhadap pemakaian bahan bakar fosil jenis solar akan diganti dengan menggunakan biodiesel B-20.

\section{TINJAUAN PUSTAKA}

Keunggulan dan Kelemahan Biodiesel B-20 Dibanding Solar

Untuk mengetahui bagaimana keunggulan dan kelemahan biodiesel B20 dibandingkan dengan solar, maka perlu pemahaman yang baik mengenai typical characteristic (sifat fisika dan sifat kimia) dari kedua jenis bahan bakar tersebut. Khusus untuk mempermudah pemahaman teknis dua jenis bahan bakar tersebut, di bawah ini akan ditinjukkan perbedaan karakteristik antara produk biodiesel B-20 dan solar B-0. [5]

Tabel 1. Perbedaan karakteristik solar dan biodiesel B-20

\begin{tabular}{|c|c|c|c|c|c|c|}
\hline \multirow[t]{2}{*}{ No } & \multirow{2}{*}{ Parameter } & \multirow{2}{*}{ Unit } & \multicolumn{2}{|c|}{ Solar (B-0) } & \multicolumn{2}{|c|}{ B-20 } \\
\hline & & & Standard & Lab Test & Standard & Lab Test \\
\hline 1 & Viscosity & $\begin{array}{l}\mathrm{mm}^{2} / \mathrm{s} \\
(\mathrm{cSt})\end{array}$ & $2,0-4,5$ & $2,95-3,35$ & $2,0-4,5$ & $2,60-2,99$ \\
\hline 2 & Flash Point & $\begin{array}{c}{ }^{\circ} \mathrm{C}, \\
\text { minimum }\end{array}$ & 52 & $56-73$ & 52 & $67-78$ \\
\hline 3 & $\begin{array}{l}\text { Cetane } \\
\text { Number }\end{array}$ & minimum & 48 & $47,8-48,8$ & 48 & $48,4-52,1$ \\
\hline 4 & Acid Value & $\begin{array}{c}\mathrm{mg}- \\
\mathrm{KOH} / \mathrm{g}, \\
\text { maximum }\end{array}$ & 0,6 & $\begin{array}{c}0,045- \\
0,050\end{array}$ & 0,6 & $0,094-0,123$ \\
\hline 5 & $\begin{array}{c}\text { Oxidation } \\
\text { Stability }\end{array}$ & $\begin{array}{l}\text { minute, } \\
\text { minimum }\end{array}$ & - & $>200$ hours & - & $\begin{array}{c}91,91- \\
107,23 \text { hours }\end{array}$ \\
\hline 6 & $\begin{array}{l}\text { Sulphur } \\
\text { Content }\end{array}$ & $\begin{array}{l}\mathrm{mg} / \mathrm{kg}, \\
\text { maximum }\end{array}$ & 0,350 & $\begin{array}{c}0,079- \\
0,289\end{array}$ & 0,350 & $0,062-0,263$ \\
\hline
\end{tabular}

Terlihat dari tabel di atas bahwa kandungan biodiesel hingga 20\% masih memenuhi spesifikasi yang ditetapkan oleh pemerintah. Bahkan karakteristik penting bahan bakar engine diesel yaitu cetane number meningkat sehingga pembakaran lebih sempurna dan flash point-nya juga semakin tinggi sehingga safety pada saat penanganan bahan bakar akan lebih baik. Juga dalam mengurangi emisi SOx akan banyak terbantu dengan menggunakan biodiesel karena kandungan sulfur campuran biodiesel B-20 akan turun.

Memang terdapat alasan teknis seperti ketahanan oksidasi dan stabilitas penyimpanan yang menghasilkan resistensi konsumen untuk menggunakan campuran biodiesel. 
Tabel 2. Heating value bahan bakar solar dan biodiesel

\begin{tabular}{|c|c|c|c|c|c|}
\hline \multirow{2}{*}{ No. } & \multirow{2}{*}{ Jenis Bahan Bakar } & \multicolumn{2}{|c|}{ Low Heating Value $($ LHV $)$} & \multicolumn{2}{c|}{ High Heating Value $($ HHV $)$} \\
\cline { 3 - 6 } & & $\mathrm{MJ} / \mathrm{kg}$ & $\mathrm{kcal} / \mathrm{kg}$ & $\mathrm{MJ} / \mathrm{kg}$ & $\mathrm{kcal} / \mathrm{kg}$ \\
\hline 1 & Solar B-0 & 42,791 & 10.227 & 45,766 & 10.938 \\
\hline 2 & Biodiesel B-20 & 41,738 & 9.975 & 44,646 & 10.670 \\
\hline 3 & Biodiesel B-100 & 37,528 & 8.969 & 40,168 & 9.600 \\
\hline
\end{tabular}

Argumentasi lain yang sering dikemukakan untuk menunjukkan kekurangan campuran biodiesel adalah nilai kalornya (heating value) yang lebih rendah, sehinga panas pembakaran campuran biodiesel akan lebih rendah daripada solar. Namun spesifikasi yang ditetapkan di Indonesia maupun spesifikasi internasional tidak menetapkan parameter heating value $\mathrm{di}$ dalamnya. Cetane number biodiesel B20 yang lebih tinggi akan menghasilkan kualitas pembakaran yang lebih baik

Namun dapat ditegaskan bahwa biodiesel B-20 telah memenuhi standar spesifikasi bahan bakar minyak jenis minyak solar yang telah ditetapkan oleh pemerintah. Oleh karena itu biodiesel B20 dinyatakan layak digunakan di Indonesia.

\section{Menghitung Torsi dan Daya Engine}

Torsi atau momen adalah gaya untuk memutarkan suatu benda pada porosnya. Adapun perumusan dari torsi adalah sebagai berikut. Apabila suatu benda berputar dan mempunyai besar gaya sentrifugal sebesar F, benda berputar pada porosnya dengan jari-jari sebesar 1 , dengan data tersebut maka: $[2,3,6,7]$

$\mathrm{T}=\mathrm{F} \times 1$

Dimana:

$\mathrm{T}=$ torsi mesin $(\mathrm{Nm})$

$\mathrm{F} \quad=$ gaya sentrifugal dari benda yang berputar $(\mathrm{N})$

$1=$ jarak benda ke pusat rotasi (m) Pengukuran torsi pada poros motor bakar (engine) menggunakan alat yang dinamakan dinamometer (dynotest). yang dapat mengkompensasi nilai kalor yang sedikit lebih kecil tersebut.

Di samping itu saat pemakaian awal sering muncul masalah penyumbatan pada filter bahan bakar atau bahkan pada nozzle injector. Hal ini disebabkan karena biodiesel memiliki sifat mild solvency (pelarut yang baik). Sifat sebagai pelarut yang baik tersebut akan memungkinkan biodiesel ini melepaskan dan melarutkan varnish dan sedimen yang menempel pada tangki bahan bakar maupun pada saluran bahan bakar akibat penggunaan solar yang sudah lama.

Daya adalah kemampuan melakukan suatu usaha atau kerja dalam setiap satuan waktu tertentu. Besarnya daya motor merupakan fungsi dari torsi yang terukur oleh dinamometer dan besar putaran poros dari motor dapat dinyatakan dengan menggunakan persamaan berikut.

$$
\mathrm{BHP}=(\mathrm{T} \times 2 \pi \times \mathrm{n}) / 60000
$$

Dimana:

$$
\begin{array}{ll}
\mathrm{BHP} & =\text { Brake Horse Power }(\mathrm{kW}) \\
\mathrm{T} & =\text { torsi mesin }(\mathrm{Nm}) \\
\mathrm{n} & =\text { putaran motor }(\mathrm{rpm})
\end{array}
$$

Sedangkan untuk mengukur BHP (HP) dengan satuan torsi lbs.ft adalah sebagai berikut:

$\mathrm{BHP}=(\mathrm{T} \times \mathrm{n}) / 5252$

Dimana:

$$
\begin{array}{ll}
\mathrm{BHP} & =\text { Brake Horse Power }(\mathrm{HP}) \\
\mathrm{T} & =\text { torsi mesin }(\mathrm{lb} . \mathrm{ft}) \\
\mathrm{n} & =\text { putaran motor }(\mathrm{rpm})
\end{array}
$$




\section{METODOLOGI PENELITIAN}

\section{Tempat dan Waktu Penelitian}

Tempat dilakukan penelitian di:

1. PT. Alun Nusantara Balikpapan (Alun Reman Centre), Jl. Mulawarman RT. 32 No. 45

Kelurahan Manggar Balikpapan.

2. PT. Universal Tekno Reksajaya (UTR) United Tractor Balikpapan, Jl. Jend. Sudirman No. 23 RT. 22 Kelurahan gunung bahagia Balikpapan.

3. PT. Tanair Pratama Nusantara Samarinda, J. Banggeris No. 87 Teluk Lerong Ulu Sungai Kunjang Samarinda.

Sedangkan waktu penelitian dilaksanakan pada bulan Januari sampai dengan Desember 2019.

\section{Obyek Penelitian}

Obyek penelitian ini adalah engine Diesel alat berat yang digunakan di perusahaan sektor tambang dan marine yaitu; Engine Volvo D9B 380, Engine Komatsu SAA6D107E-1 dan Engine Cummins Marine KTA-38.

\section{Peralatan Yang Digunakan}

Peralatan yang digunakan untuk pengujian performansi engine diesel yaitu dynamometer (dynotest).

\section{Variabel Penelitian}

Variabel dalam penelitian ini, sebagai berikut:

1. Variabel Bebas

a. Jenis engine

b.Jenis bahan bakar solar dan biodiesel B-20

c. Putaran engine [rpm]

2. Variabel Terikat

a. Torque engine ( $\mathrm{Nm}$ atau $\mathrm{lb} . \mathrm{ft})$

b. Power engine ( $\mathrm{kW}$ atau HP)

3. Variabel Kontrol

Biodiesel B-20 yang digunakan produksi PT. Pertamina (Persero).

\section{HASIL DAN PEMBAHASAN}

a.Hasil Pengukuran Dengan Dynotest

Berdasarkan hasil pengujian dari berbagai engine dengan beda merk, model dan tentunya dengan karakteristiknya yang berbeda, yang menggunakan bahan bakar solar dan biodiesel B-20, diperoleh data dalam bentuk tabel seperti berikut:

1. Engine Volvo D9B 380

Tabel 3. Data pengujian Engine Volvo D9B 380 [1]

\begin{tabular}{|c|c|c|c|}
\hline $\begin{array}{c}\text { Jenis Bahan } \\
\text { bakar }\end{array}$ & $\begin{array}{c}\text { Putaran engine } \\
(\mathbf{r p m})\end{array}$ & $\begin{array}{c}\text { Torsi maksimal } \\
(\mathbf{N m})\end{array}$ & $\begin{array}{c}\text { Daya maksimal } \\
(\mathbf{k W})\end{array}$ \\
\hline \hline Solar & 1500 & 1624 & 266 \\
\hline \multicolumn{3}{|c|}{} \\
\hline Biodiesel B-20 & 1850 & 1608 & 260 \\
\hline \multicolumn{4}{|r|}{} \\
\hline \multicolumn{2}{|c|}{ Nilai penurunan performansi } & $\mathbf{0 . 9 9 \%}$ & $\mathbf{2 , 2 6 \%}$ \\
\hline
\end{tabular}

2. Engine Komatsu SAA6D107E-1

Tabel 4. Data pengujian Engine Komatsu SAA6D107E-1 [4]

\begin{tabular}{|c|c|c|c|}
\hline $\begin{array}{c}\text { Jenis Bahan } \\
\text { bakar }\end{array}$ & $\begin{array}{c}\text { Putaran engine } \\
(\mathbf{r p m})\end{array}$ & $\begin{array}{c}\text { Torsi maksimal } \\
(\mathbf{N m})\end{array}$ & $\begin{array}{c}\text { Daya maksimal } \\
(\mathbf{k W})\end{array}$ \\
\hline \hline Solar & 1526 & 612 & 113 \\
\hline \multicolumn{4}{|c|}{} \\
\hline Biodiesel B-20 & 1958 & 549 & 106 \\
\hline & 1485 & & \\
\hline
\end{tabular}




\section{Nilai penurunan performansi}

$10.29 \%$

$6,19 \%$

3. Engine Cummins Marine KTA-38

Tabel 5. Data pengujian Engine Cummins Marine KTA-38

\begin{tabular}{|c|c|c|c|}
\hline $\begin{array}{c}\text { Jenis Bahan } \\
\text { bakar }\end{array}$ & $\begin{array}{c}\text { Putaran engine } \\
\text { (rpm) }\end{array}$ & $\begin{array}{c}\text { Torsi maksimal } \\
(\mathbf{N m})\end{array}$ & $\begin{array}{c}\text { Daya maksimal } \\
(\mathrm{kW})\end{array}$ \\
\hline \multirow[t]{2}{*}{ Solar } & 1350 & 2456 & \\
\hline & 1800 & & 400 \\
\hline \multirow[t]{2}{*}{ Biodiesel B-20 } & 1500 & 2400 & \\
\hline & 1800 & & 397 \\
\hline \multicolumn{2}{|c|}{ Nilai penurunan performansi } & $2.28 \%$ & $0,75 \%$ \\
\hline
\end{tabular}

Tabel 6. Data pengujian dari berbagai engine dengan menggunakan biodiesel

\begin{tabular}{|c|l|l|c|c|}
\hline \multirow{2}{*}{$\begin{array}{c}\text { No } \\
\cdot\end{array}$} & \multicolumn{1}{|c|}{ Jenis engine } & \multicolumn{1}{|c|}{ Teknologi Injection Pump } & \multicolumn{2}{|c|}{$\begin{array}{c}\text { Penurunan } \\
\text { Performansi } \\
(\%)\end{array}$} \\
\cline { 3 - 5 } & Tolvo D9B 380 & $\begin{array}{l}\text { Electronic Unit Injection } \\
\text { (EUI) }\end{array}$ & 0,99 & 2,26 \\
\hline 2 & Komatsu SAA6D107E-1 & $\begin{array}{l}\text { Engine Control Unit (ECU) / } \\
\text { Common rail }\end{array}$ & 10,29 & 6,19 \\
\hline 3 & $\begin{array}{l}\text { Cummins Marine KTA- } \\
38\end{array}$ & $\begin{array}{l}\text { Engine Control Unit (ECU) / } \\
\text { Common rail }\end{array}$ & 2,28 & 0,75 \\
\hline
\end{tabular}

Tabel 6 di atas menunjukan tentang jenis teknologi injection pump dan nilai penurunan performansi engine dari penggunaan bahan bakar biodiesel B-20 dibandingkan dengan solar.

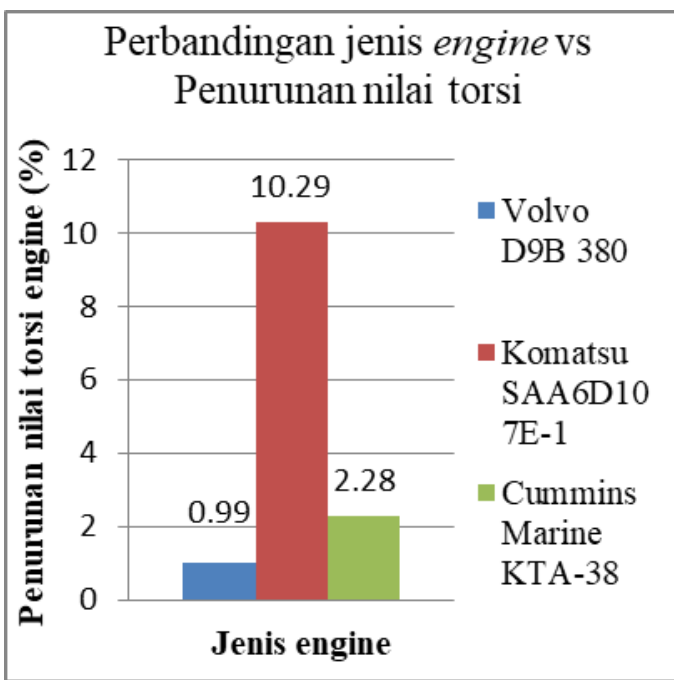

Gambar 1. Grafik perbandingan jenis engine terhadap penurunan nilai torsi dengan menggunakan bahan bakar B-20 dibandingkan solar.



Gambar 2. Perbandingan jenis engine terhadap penurunan nilai daya dengan menggunakan bahan bakar B-20 dibandingkan solar.

Terjadi penurunan nilai performansi engine (baik nilai torsi dan daya) untuk 
semua engine dan jenis injection pump apapun yang digunakan pada saat menggunakan bahan bakar biodiesel B20 dibandingkan dengan solar.

Penurunan nilai performansi engine sangat berhubungan dengan karakteristik engine untuk dapat mengadaptasi perubahan typical charactenistic dari bahan bakar biodiesel B-20 yamg tentunya tidak sama seperti solar atau bahan bakar yang digunakan sebelumnya.

Sangat diperlukan adanya suatu perubahan dari industri manufaktur pembuat engine secara keseluruhan yang meliputi berbagai aspek seperti sistem, teknologi dan konstruksi. Tujuan utamanya yaitu untuk meningkatkan tingkat kesempurnaan pembakaran di ruang bakar akibat perubahan typical characteristic bahan bakar yang berbeda, atau juga kualitas dari bahan bakar biodieselnya yang harus disesuaikan dengan typical characteristic engine.

Adanya dua alternatif perubahan dari uraian di atas, diharapkan program pemerintah tahun 2020 yang harus menggunakan biodiesel B-30 sampai dengan B-100 untuk beberapa tahun mendatang akan berjalan dengan baik.

\section{KESIMPULAN}

Berdasarkan hasil uji dari berbagai engine, maka dapat diambil beberapa kesimpulan sebagai berikut:

1. Penggantian bahan bakar dari solar ke biodiesel ini sangat baik karena dapat mengurangi penggunaan bahan bakar solar yang keberadaannya saat ini mulai menipis karena solar merupakan jenis sumber energi fosil yang tidak dapat diperbaharui, sedangkan untuk biodiesel merupakan energy yang dapat diperbaharui.

2. Hasil pengujian menunjukan bahwa untuk mencapai performansi tertinggi tiap engine akan berbeda nilai putaran engine-nya. Hal ini dikarenakan teknologi, konstruksi dan tingkat kesempumaan pembakaran di ruang bakar yang berbeda.

3. Terjadi penurunan nilai performansi untuk semua jenis engine dan injection pump apapun yang digunakan pada saat menggunakan bahan bakar biodiesel B-20 dibandingkan dengan solar.

\section{REFERENSI}

[1] Agus Waluyo, Puji Saksono, Gunawan, Analisis perbandingan penggunaan bahan bakar solar dan biodiesel B20 terhadap performansi engine Volvo D9B 380, Prosiding Seminar Nasional Inovasi Dan Aplikasi Teknologi Di Industri (SENIATI), ITN Malang, (2017)

[2] Alun Training Center, Basic Engine. Jakarta: PT. Alun, (2011)

[3] Cummins, Training Module part3Basic Mechanic Cours XXIII, PT. Altrak 1978, Balikpapan, (2011)

[4] Magfirotunnisa1, Gunawan, Puji Saksono, Analisis perbandingan penggunaan Bahan bakar solar dengan biodiesel B15 dan B20 terhadap performansi engine Komatsu SAA6D107E-1, Prosiding SNIT, Politeknik Negeri Balikpapan, (2018)

[5] Tomo, R. Choerniadi, Biofuel Melawan Ketidakpastian Energi. Bursa Ilmu,Yogyakarta, (2015)

[6] United Tractors. PT, UT School Training Module Basic Engine Diesel, two edition, PT. United Tractor, Jakarta (2011)

[7] Willard W. Pulkrabek, Engineering Fundamentals of the Internal combustion Engine (second edition), Prentice Hall, New Jersey, (2000) 